\title{
Linaje y muerte celular programadas: implicaciones en la biología del desarrollo y en biomedicina
}

\author{
Luis Alberto Gómez \\ Laboratorio de Fisiología Molecular, Instituto Nacional de Salud, Bogotá, D.C., Colombia.
}

Sydney Brenner, investigador del Instituto Salk para Estudios Biológicos en La Jolla, California, y presidente del Instituto de Ciencias Moleculares en Berkeley, Robert Horvitz del Instituto Tecnológico de Massachussets, Estados Unidos, y John Sulston del Centro Sanger de la Universidad de Cambridge, Inglaterra, fueron laureados con el premio Nobel en fisiología o medicina 2002 por sus investigaciones pioneras sobre la regulación molecular de la muerte celular programada (apoptosis), un proceso activo, regulado genéticamente, por el cual una célula se autodestruye usando su propia maquinaria molecular, lo cual ocurre como un evento fisiológico normal y se mantiene durante el desarrollo prenatal y postnatal de casi todas las células animales. Los trabajos originales de estos investigadores con el nemátodo Caenorhabditis elegans abrieron el camino a las investigaciones orientadas a identificar y dilucidar los mecanismos moleculares de la muerte y el linaje celular y sus implicaciones en la organogénesis y en la patogénesis de enfermedades comunes (1-8).

Los resultados de sus investigaciones proporcionaron las bases celulares y moleculares de los mecanismos patogénicos de varias enfermedades comunes, como el cáncer, el infarto agudo del miocardio, la insuficiencia cardiaca y algunas enfermedades neurodegenerativas y cerebrovasculares, entre otras no transmisibles, así como el mecanismo de algunas enfermedades virales y bacterianas (9-13). Los trabajos de estos tres investigadores contribuyeron a generar una explosión de investigaciones en la biología molecular del desarrollo, en la patogénesis mediada

Correspondencia:

Avenida calle 26 No. 51-60, Bogotá, D.C., Colombia

Recibido: 28/10/02; aceptado: 15/11/02 por la muerte celular programada y en nuevas estrategias de prevención y terapia de enfermedades con compromiso de los mecanismos que regulan la viabilidad y la muerte celular.

Brenner, Horvitz y Sulston investigaron el desarrollo de $C$. elegans, identificaron el mecanismo molecular que inicia la muerte celular programada y mostraron que este mecanismo es común en los procesos de desarrollo de la mayoría de las células de animales invertebrados y vertebrados, incluidos los humanos (1-3). Además, al hacer el seguimiento microscópico de la división y la migración celular después de la fertilización, pudieron reconstruir la historia anatómica completa de cada célula durante todo el proceso en que el huevo fertilizado se desarrolla en un organismo adulto (2-5). De manera similar al desarrollo de este nemátodo, todas las células del cuerpo humano se originan de una única célula, el cigoto fertilizado, y en el proceso del desarrollo de tejidos, órganos y sistemas, millones de células se dividen continuamente, crecen, migran, se especializan (se diferencian), envejecen y mueren. Este ciclo de vida celular es finamente coordinado y regulado durante todo el periodo de desarrollo de los organismos multicelulares.

Sydney Brenner inició el estudio de la biología del nemátodo $C$. elegans y demostró que cada célula del gusano adulto se deriva del cigoto por una serie invariante de divisiones celulares, migraciones, especializaciones y muertes celulares programadas, llamado colectivamente, 'linaje celular'. Además, Brenner demostró que este organismo es útil para estudiar cómo las células se van dividiendo, desarrollando, y especializando y cómo se van formando los 
órganos (organogénesis) (1). Su trabajo fue pionero en el seguimiento de las células y en el desarrollo de los órganos de $C$. elegans, produciendo mutaciones con el agente químico etilmetanosulfonato y asociando mutaciones específicas con efectos específicos sobre el desarrollo anatómico del nemátodo $(1,4)$. Algunas de las características que facilitaron el seguimiento microscópico de cada una de las 1.090 células que conforman este animal durante su desarrollo fueron: un ciclo de vida corto (1 mes), poco tiempo trnascurido desde la concepción a la madurez ( 3 días), su pequeño tamaño ( $<1 \mathrm{~mm}$ de longitud), su transparencia en todos los estadios del ciclo de vida y su fácil crecimiento en cajas de Petri. La utilización de C. elegans como modelo experimental para la investigación de los mecanismos celulares y moleculares implicados en la determinación del linaje celular, el desarrollo de órganos y sistemas y en el envejecimiento constituye uno de los principales aportes de Brenner.

John Sulston fue uno de los primeros estudiantes de Brenner y trabajó en el proyecto del linaje celular durante el desarrollo del nemátodo. Sulston describió el mapa celular completo de cómo un huevo fertilizado del nemátodo da origen a las 959 células del gusano adulto (2). También observó que durante el desarrollo normal de este animal 131 células mueren siguiendo un patrón repetitivo y descubrió la primera mutación que altera el proceso de la muerte celular programada o suicidio celular programado (5).

Robert Horvitz, por su parte, identificó y caracterizó parcialmente los primeros dos genes que inician el proceso de muerte celular programada en el nemátodo, los genes de muerte CED-3 y CED-4 (del inglés, cell death genes). Horvitz también demostró que los humanos tienen un gen similar al CED-3, un gen homólogo que codifica para una proteína que corresponde a la familia de las denominadas cisteíno-proteasas 'caspasas', la enzima caspasa-3 (6). Ahora se sabe que varios genes que controlan la muerte celular en este nemátodo (CED-1, CED-2, CED-4, CED-5, CED-6, CED-7, CED-8, CED-9, CED-10 y NUC1, entre otros), tienen su contraparte en humanos $(7,14,15)$.
Los descubrimientos de Brenner, Horvitz y Sulston son clave para la mejor comprensión de la biología del linaje celular, la muerte celular y la biología molecular del desarrollo (desde la concepción hasta el envejecimiento), así como para entender que en algunas enfermedades como el cáncer, las células escapan de los mecanismos normales que regulan la muerte celular y que en otras enfermedades, como el infarto agudo del miocardio (muerte del tejido cardiaco), las células cardiacas afrontan los mecanismos de muerte programada ante la hipoxia $(9,16)$. Este conocimiento tiene un gran impacto sobre todos los aspectos de la viabilidad, la cinética y el equilibrio celular de los tejidos y órganos de los animales. Los análisis de tejidos post mortem de pacientes y animales, así como los estudios experimentales con cultivos de células cardiacas, neuronas, células del sistema linfático y hematopoyético, entre otras, que han servido de modelos experimentales de la patogénesis de enfermedades humanas, han indicado la existencia de la muerte celular programada disminuida, por ejemplo, en cáncer, o excesiva, como en algunas enfermedades cardiovasculares y neurodegenerativas (8-13). Por tanto, el conocimiento de los mecanismos moleculares que regulan la viabilidad celular ha abierto nuevas posibilidades para el tratamiento de enfermedades en cuyo mecanismo está implicado un aumento o una disminución de la muerte celular programada. La fisiología normal de los organismos depende de un adecuado balance entre la generación de nuevas células, la especialización, el envejecimiento y la muerte celular. Aprender dónde, cuándo, cómo y porqué se alteran esos procesos celulares (conduciendo frecuentemente al crecimiento o a la pérdida celular descontrolada), es una de las tareas centrales derivadas del trabajo de estos investigadores.

En la década pasada se generaron nuevas investigaciones en biomedicina que han conducido a un mejor entendimiento de cómo las células se mueren antes o después del tiempo programado y qué genes se alteran. El fino control entre proliferación, diferenciación, envejecimiento y muerte celular parece estar regulado en gran parte por determinantes celulares, genéticos y 
moleculares que son más complejos en vertebrados en términos de heterogeneidad celular, número de genes y proteínas involucradas y en la arquitectura de los dominios de la proteínas codificadas por esos genes, tales como caspasas, proteínas antiapoptóticas de la familia $\mathrm{Bcl}$ 2, ciclinas, cinasas dependientes de ciclinas (CDK), inhibidores de cinasas dependientes de ciclinas (comp.p21), proteína del retinoblastoma, proteína p53, antígeno nuclear de célula proliferante (PCNA), receptores proteínas tirosina cinasas (PTK), nucleósido-trifosfatasas, factores de crecimiento y factores de transcripción, entre otros (14-18).

Los trabajos de los investigadores distinguidos con el premio Nobel han abierto campos de investigación en biología del desarrollo, genética, farmacología y biología molecular en busca de una mejor comprensión de los procesos básicos que ocurren durante el ciclo de vida de las células, la formación de tejidos y órganos y el envejecimiento, así como en busca del conocimiento de la fisiopatología celular de enfermedades con alteraciones en la regulación de la muerte, senescencia y diferenciación celular (19). También se ha logrado avanzar en el planteamiento de nuevas estrategias y aproximaciones para la prevención, el diagnóstico, el tratamiento y la cura de enfermedades comunes como el cáncer (8) y de enfermedades neurodegenerativas como la enfermedad de Parkinson (10). Además, se intenta reparar tejidos que han perdido una masa celular crítica para su funcionamiento adecuado a través de procedimientos de ingeniería tisular. Ahora, después de más de 40 años de trabajo con $C$. elegans, una de las perspectivas es la investigación aplicada y la profundización en el conocimiento de los mecanismos moleculares de la diferenciación, el envejecimiento y la muerte celular en organismos más complejos, como los humanos. Actualmente, se están conduciendo investigaciones para el descubrimiento de drogas cuya acción se fundamenta en el detallado conocimiento de la apoptosis y la diferenciación celular.

Entendiendo cómo transcurre el ciclo de vida de una célula, desde que se origina, crece, migra, se diferencia, se relaciona con su medio ambiente, envejece y muere, será posible comprender algunos determinantes biológicos de varias enfermedades, plantear estrategias eficaces para intervenir en la alteración de la viabilidad y función celular, así como también será más factible prevenir o limitar los factores que puedan inducir a que se desarrollen esas alteraciones. En la actualidad, se están siguiendo estrategias basadas en la investigación de los mecanismos moleculares de regulación de la viabilidad, de la diferenciación celular y del envejecimiento, identificando y analizando blancos moleculares con procedimientos de ingeniería genética y celular para operar directamente en los procesos que controlan el balance celular (renovación contra pérdida de células) y, así, convertirlas en potenciales alternativas de prevención y terapia contra enfermedades que involucran alteraciones en la regulación de la muerte celular.

\section{Referencias}

1. Brenner S. The genetics of Caenorhabditis elegans. Genetics 1974;77:71-94.

2. Sulston JE, Horvitz HR. Post-embryonic cell lineages of the nematode, Caenorhabditis elegans. Dev Biol $1977 ; 56: 110-56$.

3. Horvitz HR, Ellis HM, Sternberg PW. Programmed cell death in nematode development. Neurosci Commentaries 1982;1:56-65.

4. White JG, Horvitz HR, Sulston JE. Neurone differentiation in cell lineage mutants of Caenorhabditis elegans. Nature 1982;297:584-7.

5. Sulston JE, Schierenberg E, White JG, Thomson JN. The embryonic cell linage of the nematode Caenorhabditis elegans. Dev Biol 1983;100:64-119.

6. Ellis HM, Horvitz HR. Genetic control of programmed cell death in the nematode C. elegans. Cell 1986;44:81729.

7. Xue D, Horvitz R. Caenorhabditis elegans Ced-9 protein is a bifunctional cell-death inhibitor. Nature 1997;390:305-7.

8. Staunton M, Gaffney E. Apoptosis. Basic concepts and potential significance in human cancer. Arch Pathol Lab Med 1998;122:310-6.

9. Narula JT, Pandey P, Arbustini E, Haider N, Narula $\mathbf{N}$, Kolodgie FD, et al. Apoptosis in heart failure: release of cytochrome $\mathrm{c}$ from mitochondria and activation of 
caspase-3 in human cardiomyopathy. Proc Natl Acad Sci USA 1999;96:8144-9.

10. Mattson MP. Apoptosis in neurodegenerative disorders. Nature Rev Mol Cell Biol 2000;1:120-9.

11. Twu Ch, Liu NQ, Popik W, Bukrinsky M, Sayre J, Roberts $\mathrm{J}$, et al. Cardiomyocytes undergo apoptosis in human immunodeficiency virus cardiomyopathy through mitochondrion and death receptor-controlled pathways. Proc Natl Acad Sci USA 2002; Early Edition. 1-6. Disponible en: www.pnas.org/cgi/doi/10.1073/ pnas. 212327899 .

12. Sciorati C, Rovere P, Ferrarini M, Paolucci C, Heltai $\mathbf{S}$, Vaiani R, et al. Generation of nitric oxide by the inducible nitric oxide synthase protects gdT cells from Mycobacterium tuberculosis-induced apoptosis. J Immunol 1999;163:1570-1576.

13. Chao D, Korsmeyer S. Bcl-2 family: regulators of cell death. Annu Rev Immunol 1998;16:395-419.
14. Aravind L, Dixit VM, Koonin EV. Apoptotic molecular machinery: vastly increased complexity in vertebrates revealed by genome comparisons. Science $2001 ; 291$ : 1279-84.

15. Teller $\mathbf{H}$. Mechanisms and genes of cellular suicide. Science 1995;267:1445-9.

16. Wang B, Ho H, Lin P, Sckwarzacher S, Pollman M, Gibbons G, et al. Regression of atherosclerosis. Role of nitric oxide and apoptosis. Circulation 1999;99:123641.

17. Evan G, Littlewood T. A matter of life and cell death. Science 1998;281:1317-21.

18. Rendón LA, Schmeissner PJ, Dudaronek JM, Brown PA, Listner KM, Sakano Y, et al. Stochastic and genetic factors influence tissue-specific decline in ageing $C$. elegans. Nature 2002;419:808-14.

19. Ashkenazi A, Dixit V. Death receptors: signalling and modulation. Science 1998;281:1305-8. 